\title{
UM ESTUDO SOBRE A INFORMATIVIDADE DOS LUCROS CONTÁBEIS NA AMÉRICA LATINA
}

\author{
A STUDY ON ACCOUNTING EARNINGS INFORMATIVENESS IN \\ LATIN AMERICA
}

\author{
Alfredo Sarlo Neto ${ }^{a}$; Bruno Rossi Bassi ${ }^{b}$; André Abreu de Almeida ${ }^{c}$ \\ aProfessor da Universidade Federal do Espirito Santo, UFES; Doutorado em Ciências Contábeis pela Universidade de São Paulo, USP, \\ Vitoria, ES - Brasil; E-mail: sarloneto@ccje.ufes.br \\ ${ }^{b}$ Graduado em Ciências Contábeis pela Universidade Federal do Espirito Santo, UFES \\ Vitoria,ES-Brasil; E-mail: bbassi@gmail.com \\ 'Professor da Universidade Federal do Espírito Santo, UFES; Especialização em Auditoria de Negócios pela \\ Universidade Federal do Espirito Santo, UFES; Vitoria, ES - Brasil; E-mail: almeida@ccje.ufes.br
}

Resumo

Este estudo objetivou investigar a influência do tamanho, das oportunidades de crescimento (tendo como proxy o índice market-to-book) e endividamento sobre a informatividade dos lucros contábeis divulgados pelas empresas negociadas nos mercados acionários da Argentina, Brasil, Chile, México e Peru. Foi considerada como informatividade a intensidade da relação entre o lucro contábil e o retorno das ações, mensurada pelo coeficiente angular da reta estimada entre essas duas variáveis. A amostra foi formada por empresas não financeiras listadas nas principais bolsas latino americanas - Basa (Argentina), Bovespa (Brasil), SNSE (Chile), BMV (México) e BVL (Peru) - durante o intervalo de 2004 a 2008. Conforme esperado, os resultados encontrados indicam que a variável market-to-book (proxy para oportunidades de crescimento) influencia positivamente a informatividade dos lucros contábeis das empresas negociadas nos mercados latino-americanos. E relação às outras variáveis estudadas, tamanho e endividamento, os resultados não confirmaram a sua influência sobre a informatividade dos lucros contábeis nos mercados estudados.

Palavras-chave:Informatividade; América Latina; Tamanho da Empresa; market-to-book; Endividamento.

\section{Abstract}

This study aimed to investigate the influence of size, market-to-book and debt on the informativeness of accounting earnings reported by companies traded on the stock markets of Argentina, Brazil, Chile, Mexico and Peru. Informativeness was considered the intensity of the relationship between accounting earnings and stock returns, measured by the scope estimate between these two variables. The sample consited of non-financial companies listed on major exchanges in Latin America - Basa (Argentina), Bovespa (Brazil), SNSE (Chile), BMV (Mexico) and BVL (Peru) - during the interval from 2004 to 2008. As expected, the results indicate that the variable market-to-book positively influence the informativeness of accounting earnings reported by companies traded in Latin American markets. The results about the others variables, size end debt, have not confirmed their influence over the informativeness of accounting earnings in Latin American markets.

Keywords: Informativeness; Latin America; Size; market-to-book; Debt. 


\section{INTRODUÇÃO}

Nos mercados de capitais desenvolvidos, os trabalhos destinados a este assunto trouxeram um grande número de evidências que demonstraram exaustivamente a importância da contabilidade para os seus usuários externos. A importância da contabilidade está diretamente ligada à sua capacidade de gerar informações, ou seja, o seu potencial de transmitir informações que influenciam as expectativas de seus usuários. Segundo Sarlo Neto (2009, p. 9), “[...] Na prática da pesquisa em contabilidade, a capacidade informacional é substituída pelo termo informatividade".

A informatividade das demonstrações contábeis divulgadas para o mercado acionário brasileiro vem sendo cada vez mais estudada por pesquisadores em contabilidade. Mesmo não sendo tão extensa quanto a internacional, as pesquisas levantaram um conjunto de evidências que mostram a importância dos números contábeis divulgados para o mercado acionário nacional. Podemos citar entre os primeiros trabalhos realizados sobre a informatividade no mercado brasileiro, Schiehll (1996), Martinez (2001), Lopes (2001) e Bernardo (2001). Nestes trabalhos realizados no Brasil foram encontradas evidências, indicando que os preços reagem à divulgação das informações contábeis. Entretanto, observou-se que grupos de ações com determinadas características registram reações diferentes da maioria, tanto em magnitude, como em direção.

Muitos dos estudos sobre a informatividade e a influência de determinadas características das empresas foram feitos em pesquisas separadas, porém pesquisas realizadas sobre a informatividade de números contábeis divulgados para o mercado acionário latino-americano podem ser consideradas escassas.

Na literatura internacional podemos destacar Atiase (1985), e depois Freeman (1987), com trabalhos realizados sobre a correlação da informatividade com o tamanho das empresas. Sobre a correlação entre a informatividade e o market-to-book tem-se o trabalho de Collins e Kothari (1989). Dhaliwal et al. (1991) estudou a influência do endividamento sobre a informatividade do lucro das empresas. Assim, nesse contexto, segue a questão de pesquisa: $\boldsymbol{A}$ informatividade do lucro contábil divulgado pelas empresas negociadas nas principais bolsas latino-americanas sofreriam influência das variáveis tamanho, oportunidades de crescimento (market-to-book) e endividamento?

Dada a questão de pesquisa, o objetivo deste trabalho é verificar se as variáveis tamanho, market-to-book e endividamento exercem alguma influência sobre a informatividade dos lucros contábeis divulgados pelas empresas negociadas nas principais bolsas latino-americanas. Espera-se que o presente trabalho possa contribuir para ampliar o conhecimento sobre papel das informações contábeis divulgadas no mercado latino americano, procurando levantar evidências sobre como a informatividade dos lucros contábeis divulgados pelas empresas latino-americanas

são influenciadas pelas três variáveis estudadas.

Esta pesquisa pode ser considerada como relevante, devido aos seguintes aspectos: (i) aborda a realidade dos principais mercados acionários da América Latina, especificamente os mercados de Argentina, Brasil, Chile, México e Peru; (ii) estuda o impacto das variáveis tamanho, oportunidades de crescimento e endividamento sobre a informatividade dos lucros contábeis, tema que ainda possui poucas evidências sobre a realidade dos mercados latino-americanos; e (iii) as evidências encontradas podem contribuir com a literatura nacional, apresentando a influência das variáveis estudadas em mercados diferentes, pois esta pesquisa engloba uma amostra que 
compreende empresas no mercado latino americano; e (iv) os resultados encontrados nesta pesquisa podem ser úteis para vários usuários da informação contábil: investidores, analistas de mercado, credores e pesquisadores.

\section{REVISÃO DA LITERATURA}

Os primeiros trabalhos dedicados a verificar a relevância das informações contábeis, com destaque para o trabalho elaborado por Ball e Brown (1968), foram publicados na literatura americana. Porém, diversos autores buscaram evidenciar a relevância da contabilidade em outros mercados desenvolvidos ou menos desenvolvidos, podemos destacar entre eles: Forsgardh e Hertzen (1975) na Suécia, Firth (1981) no Reino Unido, Brown (1970) na Austrália e Knight (1983) na África do Sul. Foram muitos os trabalhos dedicados à capacidade da informatividade dos lucros na literatura internacional, entre eles, ainda podemos destacar: Collins et al. (1999), Board e Walker (1990), Strong e Walker (1993), Foster (1975) e Lev (1996).

A relevância da informação contábil foi extensamente estudada internacionalmente, tendo sido verificado por intermédio de um denso e vasto conjunto de evidências. Os trabalhos realizados presentes na literatura internacional confirmaram a relação entre a contabilidade e os preços das ações. Easton e Harris (1991) estudaram a correlação entre retorno e lucro no mercado americano de uma forma diferente. Eles acrescentaram ao modelo a variação dos lucros contábeis como variável explicativa. Foram encontrados resultados que confirmam que o retorno da ação é mais bem explicado quando a variação dos lucros contábeis é incluída ao modelo.

Contudo, as evidências descobertas refletiram uma relação entre as variações dos preços e dos lucros contábeis que não era totalmente perfeita. Mesmo havendo uma forte relação, o retorno das ações e o lucro contábil se direcionavam para uma mesma direção, mas com diferentes intensidades. Segundo Sarlo Neto (2009, p. 33), “[...] lucros/prejuízos são acompanhados por retornos positivos/negativos das ações, porém com variações diferentes. Essas evidências desencadearam um conjunto de trabalhos que investigaram a influência de diversos elementos sobre essa relação".

Primeiramente Atiase (1985), seguido por Freeman (1987), conseguiram achar evidências de que a informatividade dos lucros está diretamente relacionada com o tamanho da empresa. Assim, quanto maior a empresa, maior a informatividade da contabilidade. Também nos resultados encontrados por Chaney e Jeter (1992), os coeficientes das equações relativos à informatividade crescem de acordo com o tamanho da empresa.

Posteriormente, também no mercado americano e utilizando janelas de longo prazo para o cálculo de retornos anormais, Chaney e Jeter (1992) observaram que os coeficientes das equações relativos à informatividade foram maiores para as maiores empresas da amostra estudada. Estes resultados encontrados sugerem que a informatividade dos lucros contábeis cresce de acordo com o tamanho da empresa.

Collins e Kotthari (1989) analisaram o índice Market-to-book (MTB). O índice Marketto-Book nada mais é do que uma proxy para avaliação de oportunidades de investimentos. Collins e Kothari (1989) descobriram evidências a respeito da correlação entre a informatividade da contabilidade e o Market-to-Book. De acordo com os resultados encontrados, quanto maior a oportunidade de investimento, ou seja, maior Market-to-Book, maior a informatividade. 
Dhaliwal et al. (1991) pesquisaram a influência do nível endividamento, ou seja, considerando que o endividamento é uma proxy do risco de inadimplência, então as empresas altamente alavancadas estão associadas à alto risco. Estratificando as empresas por nível de endividamento, os autores perceberam que as empresas mais alavancadas (mais endividadas) apresentaram uma menor intensidade na relação entre lucro contábil e retorno do que as empresas menos alavancadas. Conforme os autores, empresas mais alavancadas estão associadas à maior nível de risco, portanto devem apresentar uma relação mais fraca entre lucro contábil e retorno das ações.

Recentemente, Fan e Wong (2002), nos mercados do Sudoeste asiático (Hong Kong, Indonésia, Coreia do Sul, Malásia, Cingapura, Taiwan e Tailândia), Francis et al. (2005) no mercado americano, e Sarlo Neto et. al. (2009) no mercado acionário brasileiro, pesquisaram a influência de variáveis relacionados a estrutura de propriedade (concentração de votos e diferença entre direitos de voto e de fluxo de caixa) sobre a informatividade dos lucros contábeis e também serviram como base para o modelo utilizado no presente trabalho.

Deve-se destacar que as evidências comentadas sobre as variáveis de interesse deste estudo (tamanho, oportunidades de crescimento e endividamento) foram obtidas em pesquisas presentes na literatura internacional, desenvolvidas, principalmente, sobre o mercado americano. O número de trabalhos desenvolvidos na literatura nacional que tenham como objeto o mercado latino-americano e as variáveis estudadas pode ser considerado como pequeno. Entre estes trabalhos podemos listar os estudos elaborados por Costa et. al. (2006) e Sarlo Neto et. al. (2009).

Costa et. al. (2006), pesquisou como o lucro contábil incorpora o retorno das ações de empresas argentinas, brasileiras, colombianas, peruanas e venezuelanas. Adotando o modelo de Basu (1997), os autores verificaram um reconhecimento assimétrico entre más e boas notícias, evidenciando um grau de conservadorismo no lucro contábil.

Sarlo Neto et. al. (2009) pesquisou no mercado brasileiro a influência da estrutura de propriedade sobre a informatividade dos lucros contábeis. Adicionalmente, o autor verificou a influência das variáveis tamanho, expectativa de crescimento (utilizando como proxy o índice market-to-book), endividamento e perdas sobre a informatividade dos lucros. O autor encontrou evidências de que as variáveis oportunidades de crescimento e perdas impactavam significativamente a informatividade dos lucros contábeis. Quanto às variáveis tamanho e endividamento não foram observadas a significância estatística que pudessem comprovar as suas influências.

A partir do início da última década, as pesquisas em contabilidade estão procurando evidências sobre a influência de elementos relacionados ao ambiente jurídico e institucional dos mercados sobre a relevância da informação contábil. Este evento foi previsto por Shleifer e Vishny (1997), que indicou que as pesquisas que teriam maior destaque na academia seram aquelas que demonstrassem a influência de fatores institucionais e legais no desenvolvimento do mercado de capitais. Seguindo a mesma proposta, Íudicibus e Lopes (2004) indicam que fatores institucionais e legais estão intimamente ligados ao desenvolvimento da contabilidade, e que desta maneira, a pesquisa em contabilidade deve refletir a realidade dos mercados de cada país.

A partir das indicações destes autores, pesquisas realizadas sobre os mercados latinoamericanos podem levantar evidências importantes sobre a relevância da contabilidade em ambientes que apresentam características diferentes dos mercados mais desenvolvidos. Pesquisas realizadas por Alford et al. (1993) e Ali e Hwang (2000), verificaram que diferenças 
entre os ambientes institucionais dos países podem gerar diferenças na relevância dos números contábeis divulgados.

Os ambientes institucionais dos mercados da América Latina apresentam características comuns que são: regime jurídico baseado no code-law, forte regulamentação contábil, estrutura acionária baseada no steakholder's system, pequena força da profissão contábil, alto impacto da legislação societária e fontes de financiamento baseada no crédito bancário (COSTA et. al.; 2006; p.11). Para a Federação Ibero-Americana de Bolsas - Fiab, instituição que possui a finalidade de promover a integração dos mercados latino-americanos, existem outras características que diferenciam os mercados latino-americanos dos mercados desenvolvidos, são elas: (i) transações concentradas, tanto em volume quanto em quantidade, em um pequeno número de empresas; (ii) a necessidade de fortalecimento dos mecanismos de governança corporativa; e (iii) a educação do investidor (CARNIER, 2004).

\subsection{A informatividade dos lucros contábeis}

A informatividade é definida como a correlação entre a informação contábil e os preços das ações, podendo ser representada pela associação entre o retorno dos preços das ações e o lucro contábil. Deste modo, quanto maior a relação entre o retorno das ações e o lucro contábil, maior será a informatividade do lucro divulgado pela contabilidade.

Tendo como base os modelos aplicados por diferentes autores, como Easton e Harris (1991), Francis e Schipper (1999) e Bushman et al. (2004), a relação entre o lucro contábil e o retorno das ações é habitualmente representada por uma equação em que o retorno das ações é definido como uma variável explicada e dependente da variável lucro contábil. Seguindo esta definição, esta relação assume a seguinte especificação:

$$
R_{i, j}=\mathrm{a}_{0}+\mathrm{a}_{1} \cdot L C_{i t}+\mathrm{e}_{i, t}
$$

Em que:

$\mathrm{R}_{\mathrm{i}, \mathrm{t}}=$ Retorno da ação da empresa i no período t;

$\alpha_{0}=$ Intercepto;

$\alpha_{1}=$ Coeficiente angular entre o lucro contábil e o retorno;

$\mathrm{LC}_{\mathrm{i}, \mathrm{t}}=$ Lucro contábil da empresa i no período t;

$\varepsilon_{\text {it }}=$ Erro.

Por meio da equação (1), a informatividade entre o lucro contábil e o retorno das ações é calculada pelo coeficiente angular $\left(\alpha_{1}\right)$. Este pensamento é definido por Francis et al. (2005, p. 330): "Como informatividade compreende-se o coeficiente da inclinação que relaciona retornos aos lucros ou aos dividendos, obtidos ambos das regressões entre retornos anuais e lucros anuais ou dividendos $[\ldots] "$

Considerando o mercado eficiente, os preços deveriam variar de acordo com as expectativas presentes no mercado em relação aos lucros futuros e à geração de fluxo de caixa. Neste cenário, existe uma relação entre as informações divulgadas pela contabilidade e as expectativas futuras do mercado em relação ao ativo.

Num mercado eficiente, essa relação entre o lucro contábil e o retorno das ações deveria 
ser de um para um, porém, evidências verificaram que a relação é diferente, indicando a influência de alguma variável. Este trabalho busca verificar justamente esta influência, analisando como variáveis, no caso, tamanho da empresa, oportunidades de crescimento e endividamento, influenciam essa informatividade.

\subsection{Desenvolvimento de hipóteses}

A ideia de se pesquisar a maneira como a informatividade é influenciada pelo tamanho, market-to-book e endividamento das respectivas empresas negociadas nos mercados acionários latino-americanos levou ao levantamento de três hipóteses, uma para cada variável anteriormente citada.

A primeira hipótese levantada nos leva aos estudos de Atiase (1985) e de Freeman (1987), que encontraram evidências de que a informatividade dos lucros contábeis estavam positivamente correlacionada com o tamanho da empresa. Ao analisar retornos anormais em janelas de longo prazo, Chaney e Jeter (1992) observaram que os coeficientes relativos à informatividade foram maiores para as maiores empresas da amostra estudada.

Pode-se, a partir de um raciocínio diretamente focado no mercado de capitais, perceber que um dos motivos da influência do tamanho da empresa vem do fato de que empresas maiores são as mais acompanhadas e monitoradas pelos usuários presentes no mercado, e consequentemente, mais pesquisadas pelos mesmos. Assim, por serem mais monitoradas, a informação das maiores empresas será refletida com maior rapidez nos seus respectivos preços. Desta maneira, tem-se como primeira hipótese:

\section{Ha: Otamanho influencia positivamente a informatividade dos lucros contábeis divulgados pelas empresas negociadas nas bolsas latino-americanas.}

De acordo com a hipótese acima, espera-se que as empresas maiores apresentem maior informatividade dos lucros contábeis do que as empresas menores. Desta maneira, espera-se que a relação entre o tamanho da empresa e a informatividade dos lucros contábeis seja positiva.

Collins e Kotthari (1989) utilizaram o índice market-to-book (MTB) como uma proxy para as oportunidades de crescimento econômico. O índice market-to-book é o valor de mercado de uma empresa dividido pelo seu valor patrimonial (patrimônio líquido). O market-to-book (MTB) é um índice utilizado para demonstrar a valorização da empresa no mercado acionário em relação ao seu valor contábil.

Analisando o índice market-to-book, tem-se a possibilidade de obter dois casos distintos. Obtendo como resultado um valor maior do que uma unidade (maior que 1) demonstra que o mercado reconhece que determinada empresa tem um valor maior do que está registrado nos seus dados contábeis, ou seja, o mercado está reconhecendo algo que não está sendo reconhecido pela contabilidade de maneira completa. Quando esta razão é menor que uma unidade (menor que 1) significa que o mercado não está reconhecendo os valores expressos nas demonstrações contábeis da empresa.

Por esta análise, verifica-se que a informatividade pode estar relacionada de maneira diretamente proporcional com as oportunidades de crescimento, representada pelo índice market-to-book. Assim, quanto maiores forem as oportunidades de crescimento (market-to- 
book) de uma determinada empresa, maior a informatividade do seu lucro contábil. Neste sentido, esta relação gera a segunda hipótese:

\section{Hb: As oportunidades de crescimento influenciam positivamente a informatividade dos lucros contábeis divulgados pelas empresas negociadas nas bolsas latino-americanas.}

Conforme a hipótese apresentada espera-se uma relação positiva entre o índice marketto-book, que representa as oportunidades de crescimentoe a informatividade, assim quanto maior for o índice market-to-book, maior a informatividade dos lucros contábeis.

Com base no estudo feito por Dhaliwal et al.(1991), a próxima hipótese trata da influência do endividamento sobre a informatividade do lucro contábil. Assumindo o endividamento como uma proxy para o risco de inadimplência, pode-se inferir que as empresas com maiores níveis de alavancagem podem ser associadas com maior grau de risco pelo mercado. Assim, empresas mais alavancadas (mais endividadas), por serem mais arriscadas, devem apresentar menor grau de informatividade do que as empresas menos alavancadas (menos endividadas). A partir desta relação, segue a seguinte hipótese:

Hc: $\quad$ O endividamento influencia negativamente a informatividade dos lucros contábeis divulgados pelas empresas negociadas nas bolsas latino-americanas.

Desta maneira, as empresas com alto grau de alavancagem podem apresentar menor sensibilidade na relação entre lucro contábil e retornos do que as empresas menos alavancadas. Portanto, espera-se que as empresas mais alavancadas (maior endividamento) apresentem menor informatividade dos lucros contábeis do que a com menor alavancagem.

\section{METODOLOGIA}

\subsection{Modelo}

Sendo a pesquisa empírico-analítica, utilizaram-se as evidências obtidas em forma de dados dos mercados analisados como entradas para os modelos propostos baseados em experiências anteriores para, assim, se obter os resultados das hipóteses anteriormente levantadas.

Os modelos adotados por Fan e Wong (2002), Francis et al. (2005), Sarlo Neto et al. (2009), foram adaptados de forma a procurar verificar a influência das variáveis de interesse desta pesquisa. Neste trabalho, as três hipóteses sugeridas se baseiam em três variáveis diferentes das empresas, primeiro o tamanho da empresa, segundo o índice market-to-book, e por último o endividamento da mesma.

O modelo utilizado nesta pesquisa foi estruturado com a finalidade de mensurar o impacto das variáveis estudadas (tamanho, oportunidades de crescimento, e endividamento)) sobre a informatividade dos lucros contábeis, atendendo as demandas geradas pelas hipóteses de pesquisas ( $\mathrm{Ha}, \mathrm{Hb}$ e $\mathrm{Hc}$ ). 


$$
R A_{i t}=\alpha_{0}+\beta_{l} L L A_{i, t}+\sum_{k=1}^{3} \gamma L L A_{i t} E_{-} F A T O R_{i t}+\sum_{y=2}^{5} \delta_{y} d y_{i t}+\sum_{s=2}^{5} \omega_{s} d c_{i t}+\varepsilon i t
$$

Em que:

$\mathrm{RA}_{\mathrm{it}}$ = medida de retorno anormal da ação da empresa i no período t;

LLA $_{i t}=$ lucro líquido ajustado da ação da empresa i no período t;

E_FATOR $_{\mathrm{it}}=$ excesso de fator para a empresa i no período $\mathrm{t}$;

$\mathrm{dy}_{\mathrm{it}}=$ variável binária de ano, assume valor 1 para determinado ano e 0 o contrário;

$\mathrm{dc}_{\mathrm{it}}=$ variável binária de país, assume valor 1 para determinado país e 0 o contrário;

$\mathrm{e}_{\mathrm{it}}=$ erro para a empresa i no período $\mathrm{t}$.

Com a intenção de verificar o efeito de cada variável estudada sobre a informatividade dos lucros contábeis, a equação (1) inicialmente apresentada foi modificada para a equação (2). Foram adicionadas três interações entre o lucro líquido e as variáveis tamanho, , marketto-book (proxy para oportunidades de crescimento)e endividamento, de forma a capturar a influência de cada uma das variáveis sobre a informatividade.

Os coeficientes de interesse deste modelo são os coeficientes $\gamma_{1}, \gamma_{2}$ e $\gamma_{3}$ que mensuram, respectivamente, a informatividade do lucro contábil condicionada às variáveis de estudo desta pesquisa: tamanho, oportunidades de crescimento (market-to-book) e endividamento. Adotando uma postura mai conservadora, este estudo adotou apenas os níveis de $1 \%$ e $5 \%$ para confirmar a significância estatística das variáveis.

No modelo foram adicionadas, como variáveis de controle, variáveis dummy para cada ano da amostra $(d y)$ e para cada país $(d c)$. A inserção de variáveis de controle para os anos e países tem a intenção de eliminar qualquer evento macroeconômico ou característica de cada mercado que possam influenciar a relação entre o retorno das ações e as variáveis de interesse do modelo.

Com a intenção de mitigar os efeitos de uma possível heterocedasiticade nas séries de dados adotados, comum em séries de variáveis econômicas e financeiras, os coeficientes estimados pelo modelo foram corrigidos pelo método proposto por White (1980). Correlacionado às hipóteses de pesquisa elaboradas, esperam-se, para as variáveis interativas do modelo utilizado, os seguintes resultados:

\begin{tabular}{|c|c|c|}
\hline Hipóteses & Variável & Coeficiente \\
\hline $\mathrm{Ha}$ & LLA.TAM & $(+)$ \\
\hline $\mathrm{Hb}$ & LLA.MTB & $(+)$ \\
\hline $\mathrm{Hc}$ & LLA.END & $(-)$ \\
\hline
\end{tabular}

Quadro 1: Resumo resultados esperados por hipótese e por modelo

Pelos resultados esperados, conforme o Quadro 1, as variáveis interativas que representam a interação entre o lucro e tamanho (LLA.TAM) e entre o lucro e oportunidades de crescimento (LLA.MTB) devem apresentar coeficientes positivos, de forma a confirmar o impacto positivo das variáveis tamanho e market-to-book sobre a informatividade dos lucros contábeis. De forma oposta, para a variável interativa entre o lucro e endividamento (LLA. END) espera-se um coeficiente negativo, evidenciando o impacto do endividamento negativo 
sobre a informatividade dos lucros contábeis.

\subsection{Seleção das variáveis}

Retorno Anormal (RA): Como medida para o retorno das ações foi adotado o retorno anormal (RA). Entre as formas indicadas por Soares (2002), adotou-se o retorno da ação ajustado pelo retorno do mercado, procedimento similar ao adotado por Fan e Wang (2002), Francis et. al. (2005) e Sarlo Neto (2009). O retorno anormal representa o excesso de retorno da empresa em relação ao mercado em determinado período.

$$
R A_{i, t}=R_{i, t}-R M_{t}
$$

Em que, $\mathrm{RA}_{\mathrm{i}, \mathrm{t}}$ é o retorno anormal da ação da empresa i no período $\mathrm{t} ; \mathrm{R}_{\mathrm{i}, \mathrm{t}}$ é o retorno da ação da empresa i no período t; e $\mathrm{RM}_{\mathrm{i}, \mathrm{t}}$ é o retorno do mercado onde a empresa é listada no período t. Para os retornos de cada um dos mercados estudados foram utilizadas as variações dos seguintes índices de mercado:

\begin{tabular}{|c|c|}
\hline País & Índice de Mercado \\
\hline Argentina & MERVAL \\
\hline Brasil & IBOVESPA \\
\hline Chile & IPSA \\
\hline México & INMEX \\
\hline Peru & IGBVL \\
\hline
\end{tabular}

Quadro 2: Relação de Índice por Mercado

Lucro Líquido Ajustado (LLA): é o lucro líquido da empresa divulgado no exercício ajustado pelo valor de mercado da empresa.

$$
L L A_{i, t}=\frac{L L_{i, t}}{V M_{i, t-1}}
$$

Em que, LLA $_{\mathrm{i}, \mathrm{t}}$ é o lucro líquido ajustado da ação da empresa i no período t; $\mathrm{LL}_{\mathrm{i}, \mathrm{t}}$ é o lucro líquido da empresa i no período t; e $\mathrm{VM}_{\mathrm{i}, t-1}$ é o valor de mercado da empresa i no período $\mathrm{t}-1$.

Excesso de Fator (E_Fator): variável que representa a posição de excesso de um fator (variável) em relação a mediana de cada mercado. Como em cada mercado estudado, cada um dos fatores estudados podem apresentar distribuições diferentes tornando-os incomparáveis. Assim, foram utilizados valores relativos dos fatores em relação ao mercado em que a empresa está inserida, determinando a importância do fator somente para aquele mercado.

$$
E_{-} \text {FATOR }_{i, t}=\text { FATOR }_{i, T}-\text { Md_FATOR }{ }_{m, t}
$$

Em que, E_FATORi,t é excesso de determinado fator da empresa i no período t; FATORi,t é fator pesquisa (tamanho, market-to-book e endividamento) da empresa i no período t; e Md_ FATORm,t é a mediana do fator no mercado no qual a empresa é negociada no período $t$.

A confecção desta variável permite isolar a diferença de escala dos fatores entre os mercados analisados. Se variáveis de diferentes mercados fossem comparadas sem nenhum 
ajuste, haveria o problema de escala, pois empresas de mercados diferentes podem apresentar distribuições de valores em escalas muito diferentes. Por exemplo: a empresa "A" e a empresa "B" podem ser consideradas muito grandes (valor de mercado) nos seus respectivos mercados, porém devido às diferenças de escalas das distribuições da variável tamanho (valor de mercado) entre os mercados, a empresa " $A$ " pode ser muito maior do que a empresa "B". Como o problema de escala prejudica a comparação das distribuições de valores das variáveis e, consequentemente, de suas medidas estatísticas (média mediana e desvio-padrão), o interesse desta pesquisa não é capturar a diferença entre empresas grandes e pequenas de mercados diferentes, mas a diferença entre empresas negociadas em um mesmo mercado. Assim, para reduzir o impacto da discrepância de escala entre os mercados sobre a estimativa dos coeficientes dos modelos, foi adotada uma medida relativa (diferença pela mediana).

Tamanho (TAM): foi adotada como uma proxy do tamanho da empresa o logaritmo natural do valor de mercado da empresa.

$$
T A M_{i, t}=\ln \left(V M_{i, t}\right)
$$

Em que, TAMi ${ }_{, t}$ é o tamanho da empresa i no período $t ; \ln \left(V_{\mathrm{i}, t}\right)$ é logaritmo natural do valor de mercado da empresa i no período $t$.

Market-to-Book (MTB): relação entre valor de mercado dos ativos divididos pelo valor contábil do patrimônio líquido.

$$
M T B_{i, t}=\frac{L L_{i, t}}{V \text { Cont }_{i, t}}
$$

Em que, $\mathrm{MTB}_{\mathrm{i}, \mathrm{t}}$ é o Market-to-Book da empresa i no período t; $\mathrm{VM}_{\mathrm{i}, \mathrm{t}}$ é o valor de mercado da empresa i no período t; e VCont ${ }_{\mathrm{i}, \mathrm{t}}$ é o valor contábil do Patrimônio Líquido da empresa i no período t.

Endividamento (END): relação entre capital de terceiros e passivo total, calculados a cada exercício a partir dos valores registrados no Balanço Patrimonial da empresa;

$$
E N D_{i, t}=\frac{C T_{i, t}}{P T_{i, t}}
$$

Em que, $\mathrm{END}_{\mathrm{i}, \mathrm{t}}$ é o endividamento da empresa i no período t; $\mathrm{CT}_{\mathrm{i}, \mathrm{t}}$ é o capital de terceiros da empresa i no período t; e $\mathrm{PT}_{\mathrm{i}, \mathrm{t}}$ é o passivo total da empresa i no período $\mathrm{t}$.

Para isolar o efeito sobre a variável dependente, foram agregadas aos modelos variáveis binárias (dummy). Foram eleitas como variáveis dummy as seguintes variáveis:

- Ano (dy): representado por um conjunto de variáveis binárias. As variáveis assumem valor igual a 1 (um) para determinado ano e 0 (zero) para os outros anos. 
- País (dc): os diferentes países de negociação das empresas selecionadas na amostra de trabalho foram representados por um conjunto de variáveis binárias. As variáveis assumem valor igual a 1 (um) para as empresas que participam de determinado mercado/país e 0 (zero) para as empresas de outros países.

As variáveis binárias (dummy) foram incluídas com a intenção de eliminar qualquer evento macroeconômico, relacionados à algum ano ou país, que possam influenciar a relação entre o retorno das ações e os lucros contábeis que compõem a amostra.

Ao final da coleta das informações foram adotadas medidas corretivas sobre os outliers observados. Como visto por Bussab e Moretin (2005, p. 50) "Do ponto de vista estatístico, um outlier pode ser produto de um erro de observações ou de arredondamento." As medidas adotadas foram:

i. Excluídas todas as ações que apresentassem lucro líquido ajustado (LLA) inferior a $-1,5$ ou superior a 1,5. Este procedimento foi similar ao aplicado por Easton e Harris (1991), Francis et al. (2005) e Sarlo Neto (2009); e

ii. Winsorização das variáveis tamanho(TAM), market-to-book(MTB) e endividamento (END), no limite inferior de $2 \%$ e superior de $98 \%$. A winsorização consiste em um procedimento proposto pelo bioestatístico C.P. Winsor. Por meio deste procedimento, os registros com valores acima ou abaixo de determinados limites, inferiores ou superiores, são substituídos pelo maior e menor valor remanescente do limite estabelecido.

\subsection{Seleção da amostra}

Foram selecionadas empresas não financeiras de cinco $^{1}$ países na América Latina (Argentina, Brasil, Chile, México e Peru) nos anos de 2004 a 2008. Os critérios adotados para a inclusão de uma empresa na amostra de trabalho da pesquisa foram:

- Estar listada na principal bolsa de valores de cada um dos países selecionados para a pesquisa (ver Tabela 1);

- apresentar todos os dados necessários para a confecção das variáveis utilizadas nos modelos; e

- não apresentar patrimônio negativo (passivo a descoberto) em nenhum dos anos da amplitude da amostra.

A partir da aplicação dos critérios de empresas a amostra de trabalho da pesquisa apresentou a seguinte composição de observações por países:

Tabela 1: $\mathrm{N}^{\mathrm{o}}$ de Observações por Bolsa/País na Amostra de Trabalho

\begin{tabular}{c|c|c|c|c|c|c|c|c}
\hline País & Bolsa & $\mathbf{2 0 0 4}$ & $\mathbf{2 0 0 5}$ & $\mathbf{2 0 0 6}$ & $\mathbf{2 0 0 7}$ & $\mathbf{2 0 0 8}$ & Total & \% \\
\hline Argentina & BASE & 30 & 29 & 32 & 41 & 37 & 169 & 11,96 \\
\hline Brasil & BOVESPA & 70 & 76 & 102 & 146 & 186 & 580 & 41,07 \\
\hline Chile & SNSE & 73 & 71 & 65 & 61 & 58 & 328 & 23,23 \\
\hline México & BMV & 33 & 33 & 44 & 44 & 35 & 189 & 13,38 \\
\hline Peru & BVL & 24 & 25 & 30 & 34 & 33 & 146 & 10,34 \\
\hline \multicolumn{2}{r|}{ Total: } & $\mathbf{2 3 0}$ & $\mathbf{2 3 4}$ & $\mathbf{2 7 3}$ & $\mathbf{3 2 6}$ & $\mathbf{3 4 9}$ & $\mathbf{1 . 4 1 2}$ & $\mathbf{1 0 0 , 0 0}$ \\
\hline
\end{tabular}

Foi levantada, de acordo com os critérios de seleção adotados, uma amostra de trabalho com 1.412 observações (empresa/ano) para os cinco mercados/países analisados. Observa-se, 
pela Tabela 1, a presença expressiva $(41,07 \%)$ de observações do mercado brasileiro.

Como a amostra de trabalho é composta por empresas negociadas em diferentes mercados, a mesma foi segregada em 5 sub-amostras, uma sub-amostra para cada mercado/ país. Este procedimento é de interesse da pesquisa, possibilitando que o modelo (2) possa ser estimado em duas abordagens: (i) Pooled, estimativa sobre os dados de todos os mercados conjunto, de forma a levantar evidências sobre a América Latina com um todo; e (ii) individual, estimativa sobre cada uma das sub-amostras, possibilitando o levantamento de evidências específicas de cada um dos mercados estudados.

\section{RESULTADOS ENCONTRADOS}

\subsection{Estatística descritiva e análise de correlação}

Para o conjunto de dados extraídos, de acordo com os procedimentos indicados pela metodologia, seguem abaixo as estatísticas descritivas das variáveis utilizadas nos modelos adotados:

Tabela 2: Estatística Descritiva

\begin{tabular}{c|ccccc}
\hline & RA & LLA & TAM & MTB & END \\
\hline Média & $-0,67$ & 0,09 & 6,01 & 2,19 & $52,22 \%$ \\
Desvio & 75,47 & 0,15 & 1,65 & 2,73 & $18,51 \%$ \\
Mediana & $-9,36$ & 0,08 & 6,13 & 1,53 & $53,2 \%$ \\
Mínimo & $-210,59$ & $-0,77$ & 0,17 & 0,01 & $0,16 \%$ \\
Máximo & 486,92 & 1,29 & 10,50 & 36,30 & $95,70 \%$ \\
N $^{\circ}$ Obs & 1.412 & 1.412 & 1.412 & 1.412 & 1.412 \\
\hline
\end{tabular}

De forma a calcular o grau de associação entre as variáveis estudadas, foram calculados os coeficientes de correlação de Pearson. Os valores das correlações servem como uma referência preliminar das relações existentes entre as variáveis adotadas na pesquisa.

Tabela 3: Correlação entre as variáveis

\begin{tabular}{c|ccccc}
\hline & RA & LLA & TAM & MTB & END \\
\hline RA & 1.0000 & - & - & - & - \\
LLA & $0.3224^{*}$ & 1.0000 & - & - & - \\
TAM & -0.0309 & -0.0398 & 1.0000 & - & - \\
MTB & $0.2389 *$ & -0.0033 & $0.1171^{*}$ & 1.0000 & - \\
END & $-0.0609 * *$ & $-0.1532^{*}$ & $0.1637^{*}$ & $0.2257 *$ & 1.0000 \\
\hline
\end{tabular}

Notas: (i) Coeficiente de Correlação de Pearson. (ii) Os asteriscos indicam o nível de significância dos coeficientes: $*(1 \%)$ e $* *(5 \%)$.

Na tabela 3, na qual se apresentam as correlações entre as variáveis, observa-se que a variável Retorno Anormal (RA) possui correlação negativa com as variáveis tamanho (TAM) e endividamento (END), e positiva com a variável market-to-book (MTB). Apesar da variável tamanho (TAM) apresentar correlação negativa, a mesma não apresentou significância estatística. As outras variáveis, market-to-book (MTB) e endividamento (END) apresentaram significância estatística ( $1 \%$ e $5 \%$ respectivamente) e valores, positivo e negativo, respectivamente. 
Tabela 4: Média das Variáveis por Sub-Amostra (mercado)

\begin{tabular}{c|ccccc}
\hline Sub-Amostra & RA & LLA & TAM & MTB & END \\
\hline Argentina & $-26,67$ & 0,12 & 4,94 & 1,24 & $47,09 \%$ \\
Brasil & $-9,01$ & 0,08 & 6,38 & 2,53 & $57,55 \%$ \\
Chile & 1,48 & 0,09 & 5,78 & 1,93 & $46,27 \%$ \\
México & 12,72 & 0,08 & 6,89 & 2,16 & $53,95 \%$ \\
Peru & 40,32 & 0,13 & 5,10 & 2,61 & $48,09 \%$ \\
\hline America Latina & $-0,67$ & 0,09 & 6,01 & 2,19 & $52,22 \%$ \\
\hline
\end{tabular}

Os números tabulados na tabela 4 apresentam uma grande dispersão entre os retornos anormais (RA) médios calculados para os mercados/países no período analisado, enquanto o menor retorno anormal foi observado no mercado argentino $(-26,67)$, o maior foi registrado no mercado peruano (40,32). De forma oposta, as outras variáveis de interesse do estudo registraram uma menor dispersão, apresentando valores próximos às médias registradas para a amostra de trabalho (América Latina). Em relação a variável tamanho (TAM), o maior valor foi observado no México $(6,89)$. Enquanto o maior valor médio para as oportunidades de crescimento (representado pelo MTB) foi registrado pelo mercado do Peru $(2,61)$, o maior endividamento (END) médio foi apresentado no mercado brasileiro $(57,55 \%)$.

\subsection{Resultados encontrados sobre a amostra de trabalho (America Latina)}

Seguindo a abordagem de estimativa Pooled, para se verificar o resultado dos dados nas empresas selecionadas nos mercados da América Latina o modelo (2) foi aplicado sobre a amostra de trabalho.

A partir dos valores estimados pelo modelo, descritos na Tabela 4, observa-se que o Lucro Líquido Ajustado (LLA) apresentou valor positivo e significativo (1\%). Este resultado corrobora com as evidências, encontradas na literatura internacional e nacional, de que o lucro contábil é positivamente relacionado com os retornos das ações.

Em relação aos valores estimados para as três variáveis de estudo desta pesquisa, temos os seguintes resultados:

- A variável interativa entre o lucro líquido ajustado e o tamanho (LLA.E_TAM) apresentou sinal negativo e significante estatisticamente (5\%). Este resultado é oposto do esperado pela hipótese (ha), e indica que quanto maior a empresa em menor a informatividade dos lucros contábeis.

- Em relação à variável interativa entre o lucro líquido ajustado e o market-to-book (LLA.E_MTB) foi estimado uma valor positivo, conforme esperado, e significante estatisticamente $(1 \%)$. O resultado indica que para as empresas da amostra, quanto maior o índice market-to-book, maior a informatividade dos lucros contábeis.

- Para a variável interativa entre o lucro líquido ajustado e endividamento (LLA.E_ END), o valor estimado foi negativo, conforme esperado, porém não foi significativo estatisticamente. Este resultado não confirma a influência negativa do endividamento sobre a informatividade dos lucros contábeis.

Os resultados sobre a amostra de trabalho, indicam que para as empresas negociadas nos principais mercados da América Latina, a informatividade é negativamente relacionada com o 
Um Estudo sobre a Informatividade dos Lucros Contábeis na

tamanho e positivamente relacionada com o market-to-book.

Tabela 5: Resultados Gerais do Modelo sobre a Amostra de Trabalho

\begin{tabular}{|c|c|}
\hline & América Latina \\
\hline Const. & $-39.7914^{*}$ \\
\hline & (6.8530) \\
\hline LLA & $147.4687^{*}$ \\
\hline & (19.583) \\
\hline LLA.E_TAM & $-20.1009 * *$ \\
\hline & (8.779) \\
\hline LLA.E_MTB & $80.1935 *$ \\
\hline & (10.015) \\
\hline LLA.E_END & -1.4829 \\
\hline & $(0.8894)$ \\
\hline Brasil & $22.2453^{*}$ \\
\hline & $(7.0060)$ \\
\hline Chile & $30.8070^{*}$ \\
\hline & $(7.0845)$ \\
\hline México & $44.0059 *$ \\
\hline & 7.700529 \\
\hline Peru & $58.0950 *$ \\
\hline & $(9.4038)$ \\
\hline 2005 & $-16.9201^{*}$ \\
\hline & $(5.5024)$ \\
\hline 2006 & -11.4532 \\
\hline & $(6.4639)$ \\
\hline 2007 & $26.6679 *$ \\
\hline & $(5.1572)$ \\
\hline 2008 & $-34.4835^{*}$ \\
\hline & $(4.7407)$ \\
\hline $\mathrm{R}^{2}$ ajust. & $33,35 \%$ \\
\hline Estatística-F & $44,53^{*}$ \\
\hline $\mathrm{n}^{\circ}$ Obs. & 1412 \\
\hline
\end{tabular}

Notas: (i) os valores em parênteses indicam o erro padrão robusto dos coeficientes; (ii) asteriscos indicam o nível de significância dos coeficientes: * $(1 \%)$ e ** $(5 \%)$; (iii) $\mathrm{R}^{2}$-ajust é o $\mathrm{R}$ ao quadrado ajustado do modelo.

Em relação aos valores estimados para as três variáveis de estudo desta pesquisa, foram obtidos os seguintes resultados:

- Tamanho: a variável interativa entre o lucro líquido ajustado e o tamanho (LLA.E_ 
TAM) apresentou sinal negativo e significante estatisticamente (5\%). Apesar de significativo, o resultado encontrado é oposto ao resultado esperado. Assim, o resultado encontrado não confirma a hipótese $(\mathrm{Ha})$. O sinal estimado para a variável (LLA.E_TAM) indica que quanto maior a empresa, menor a informatividade dos lucros contábeis.

- Oportunidades de Crescimento: em relação à variável interativa entre o lucro líquido ajustado e o índice market-to-book (LLA.E_MTB), utilizado como proxy para as oportunidades de crescimento, foi estimado um valor positivo e significante estatisticamente $(1 \%)$. O resultado encontrado vai de encontro ao conforme esperado e confirma a hipótese $(\mathrm{Hb})$. $\mathrm{O}$ resultado indica que para as empresas da amostra, quanto maiores forem as oportunidades de crescimento, maior será a informatividade dos lucros contábeis.

- Endividamento: Para a variável interativa entre o lucro líquido ajustado e endividamento (LLA.E_END), o valor estimado foi negativo, como esperado, porém não foi significativo estatisticamente. Apesar de apresentar o sinal esperado, o fato de não ser significante estatisticamente faz com o resultado encontrado não confirme a hipótese (Hc). Assim, este resultado não gerou evidências que possam confirmar a influência negativa do endividamento sobre a informatividade dos lucros contábeis.

Os resultados sobre a amostra de trabalho indicam que para as empresas negociadas nos mercados estudados, a informatividade é negativamente relacionada com a variável tamanho (TAM) e positivamente relacionada com a variável oportunidades de crescimento (MTB). Desta maneira, os resultados indicam que os lucros contábeis divulgados pelas maiores empresas possuem menor infomatividade, e de forma inversa, os lucros contábeis divulgados pelas empresas que possuem maiores oportunidades de crescimento possuem maior infomatividade.

Em relação às três hipóteses de trabalho lançadas pela pesquisa, os resultados confirmaram somente a hipótese $(\mathrm{Hb})$, enquanto as outras duas hipóteses, $(\mathrm{Ha})$ e ( $\mathrm{Hc})$, não foram confirmadas. Desta maneira, entre as variáveis estudadas, somente a influência da variável oportunidades de crescimento (MTB) sobre a informatividade dos lucros contábeis foi confirmada.

A confirmação da hipótese $(\mathrm{Hb})$ sugere que, nos mercados estudados, as empresas que possuem maiores oportunidades de crescimento, possuem maior nível de infomatividade dos lucros contábeis do que as empresas com menores oportunidades de crescimento.

Em relação às variáveis de controle, todas as variáreis binárias relativas aos países $(d c)$ apresentaram valores significantes (1\%). Este resultado indica que a informatividade dos lucros contábeis é diferente em todos os países que compõem a amostra. Esta evidência indica que, apesar de apresentarem algumas similaridades, as características individuais da estrutura de cada um dos mercados analisados podem afetar o nível de informatividade dos lucros contábeis.

Quanto à utilização das variáveis binárias relativas aos anos $(d y)$, somente o resultado referente ao ano de 2006 não apresentou significância estatística. Este resultado indica que em cada ano, com exceção do ano de 2006, houve eventos que impactaram a informatividade dos lucros contábeis das empresas negociadas nos mercados latino-americanos.

\subsection{Resultados encontrados sobre sub-amostras}

Adotando a abordagem de estimativa individual, o modelo (2) foi aplicado sobre as 
subamostras dos países com a finalidade específica de mensurar o impacto das três variáveis de interesse de estudo sobre a informatividade dos lucros contábeis divulgados em cada um dos mercados selecionados para o estudo: Argentina, Brasil, Chile, México e Peru.

$\mathrm{Na}$ Tabela 5, se encontram listados os resultados da aplicação do modelo sobre as subamostras de cada um dos países estudados. De forma similar ao resultado encontrado sobre a amostra de trabalho, a variável Lucro Líquido Ajustado apresentou valor positivo e significante (1\%) para todas as subamostras. Este resultado indica que o lucro contábil é positivamente relacionado com os retornos das ações em todos os mercados analisados na América Latina.

Tabela 5: Resultado do Modelo por País

\begin{tabular}{|c|c|c|c|c|c|}
\hline & Argentina & Brasil & Chile & México & Peru \\
\hline \multirow[t]{2}{*}{ Const. } & $-24.7896^{*}$ & 2.1954 & 0.1835 & $-32.9618^{*}$ & $-47.6919 *$ \\
\hline & (6.6958) & (7.8897) & (8.1688) & (10.2231) & (13.2819) \\
\hline \multirow[t]{2}{*}{ LLA } & $104.4415^{*}$ & $117.5761^{*}$ & $143.7653^{*}$ & $232.5487^{*}$ & $326.1289 *$ \\
\hline & (22.8497) & (23.1308) & (44.9167) & (59.7818) & (54.1622) \\
\hline \multirow[t]{2}{*}{ LLA.E_TAM } & -0.7726 & -20.2814 & -35.7386 & -22.3123 & 30.5374 \\
\hline & (8.4463) & (10.7192) & $(30.2161)$ & (16.0694) & $(27.5580)$ \\
\hline \multirow[t]{2}{*}{ LLA.E_MTB } & $112.8016^{* *}$ & $42.3658^{*}$ & $55.8841^{* *}$ & $108.0484^{* *}$ & $70.0787^{*}$ \\
\hline & (45.1551) & (13.5471) & (22.2101) & (45.8294) & (10.8107) \\
\hline \multirow[t]{2}{*}{ LLA.E_END } & -0.8201 & 0.0200 & 0.8633 & -4.5684 & 1.1029 \\
\hline & (0.8371) & (0.9639) & $(1.8000)$ & $(2.3780)$ & (2.5991) \\
\hline \multirow[t]{2}{*}{2005} & 0.5784 & $-22.9296^{* *}$ & $-20.9236^{* *}$ & $-18.8881 * *$ & 3.0283 \\
\hline & 9.4649 & (11.0255) & $(9.6471)$ & $(8,0396)$ & (17.5679) \\
\hline \multirow[t]{2}{*}{2006} & $-171.9670^{*}$ & $-31.0282 *$ & $-23.6877^{*}$ & $86.2192 *$ & $111.7236^{*}$ \\
\hline & (8.1829) & $(9.4537)$ & $(8,9241)$ & (8.1165) & $(18.9281)$ \\
\hline \multirow[t]{2}{*}{2007} & $52.6029 *$ & $33.9779 *$ & $-16.0128 * *$ & $36.2941 *$ & $29.2127 * *$ \\
\hline & (10.5139) & $(8.3302)$ & (7.9932) & (11.1568) & $(15.9968)$ \\
\hline \multirow[t]{2}{*}{2008} & 12.0355 & $-72.5004 *$ & -12.4990 & -13.1462 & $40.4132 *$ \\
\hline & (6.7474) & (7.8434) & (7.8257) & (9.1922) & (12.5918) \\
\hline $\mathrm{R}^{2}$ ajust. & $79,94 \%$ & $48,20 \%$ & $21,04 \%$ & $62,24 \%$ & $72,36 \%$ \\
\hline Estatística-F & $117,09^{*}$ & $89,28 *$ & $2,70^{*}$ & $40,10^{*}$ & $51,51^{*}$ \\
\hline $\mathrm{n}^{\circ}$ Obs. & 169 & 580 & 328 & 189 & 146 \\
\hline
\end{tabular}

Notas: (i) os valores em parênteses indicam o erro padrão robusto dos coeficientes; (ii) os asteriscos indicam o nível de significância dos coeficientes: * (1\%) e ** (5\%); (iii) $\mathrm{R}^{2}$-ajust é o $\mathrm{R}$ ao quadrado ajustado do modelo. resultados:

Em relação às variáveis de interesse do estudo, foram encontrados os seguintes

- Tamanho: diferentemente do resultado encontrado sobre a amostra de trabalho (América Latina), para a variável tamanho (TAM) não houve registro de valores estatisticamente significativos em nenhuma das sub-amostras analisadas. Assim, não se pode levantar nenhuma evidência sobre a influência das variáveis tamanho (TAM) sobre a informatividade dos lucros contábeis nos países analisados. Este resultado não confirma a hipótese (Ha), de que a variável tamanho influencia a informatividade 
dos lucros contábeis das empresas negociadas nos mercados analisados.

- Oportunidades de Crescimento: a variável oportunidades de crescimento, representado pelo índice market-to-book (MTB), apresentou valores de acordo com o esperado e similar ao encontrado sobre a amostra de trabalho (América Latina). De acordo com os resultados, a variável oportunidades de crescimento apresentou valores positivos e significantes em todos os países analisados. O resultado encontrado confirma a hipótese $(\mathrm{Hb})$ para todos os mercados estudados, indicando que a informatividade dos lucros contábeis é positivamente relacionada com as oportunidades de crescimento.

- Endividamento: para a variável endividamento (END) não houve registro de valores estatisticamente significativos em nenhuma das sub-amostras observadas. Assim, não se pode levantar nenhuma evidência sobre a influência da variável endividamento sobre a informatividade dos lucros contábeis dos países analisados. Estes resultados não confirmam a hipótese $(\mathrm{Hc})$ de que a variável endividamento influencia negativamente a informatividade dos lucros contábeis das empresas negociadas nos principais mercados da América Latina.

Os resultados encontrados nas sub-amostras dos mercados/países foram uniformes. Em todas as sub-amostras foram verificadas, em relação as variáveis de interesse do estudo, apenas a influência da variável oportunidades de crescimento, representada pelo índice market-to-book (MTB). Em relação às outras duas variáveis, tamanho (TAM) e endividamento (END), não foram observadas as suas influências por não apresentarem significância estatisticamente em todas as sub-amostras.

Quanto aos valores gerados para as variáveis binárias relativas aos anos ( $d y)$ não houve uma uniformidade nos resultados tal como observado nas variáveis de interesse do estudo. Os resultados obtidos sobre as variáveis anos $(d y)$ indicam que eventos ocorridos em cada ano influenciaram os mercados de formas diferentes. Desta maneira, o impacto diferente de cada ano sobre cada mercado pode ser um reflexo de eventos específicos e internos ocorridos em cada um destes mercados.

\section{CONCLUSÕES}

O objetivo deste estudo foi verificar a influência das variáveis tamanho, market-to-book e endividamento sobre a informatividade dos lucros contábeis das empresas não financeiras negociadas nos principais mercados acionários latino-americanos (Argentina, Brasil, Chile, México e Peru).

As evidências foram levantadas sobre duas abordagens, uma sobre os dados agregados da América latina, onde todos os mercados são analisados de forma conjunta (Pooled), e outra, onde cada mercado/país foi analisado separadamente.

Inicialmente, os resultados encontrados sobre todas as amostras confirmaram que os lucros contábeis são relevantes para explicar os retornos das ações. Estes resultados corroboram, para estes mercados, as numerosas evidências encontradas na literatura internacional (Forsgardh e Hertzen; 1975, Firth; 1981, Brown; 1970, Knight; 1983, Collins et al.;1999, Board e Walker; 1990, Strong e Walker; 1993, Foster; 1975 e Lev; 1996). 
De acordo com as evidências empíricas encontradas sobre os dados agregados, a amostra América Latina, pode-se apresentar os resultados relativos às hipóteses de trabalho levantadas:

\begin{tabular}{|c|c|c|}
\hline$\#$ & Hipóteses & Resultados \\
\hline $\mathrm{Ha}$ & $\begin{array}{l}\text { O tamanho influencia positivamente a informatividade dos lucros contábeis } \\
\text { divulgados pelas empresas negociadas nas bolsas latino-americanas }\end{array}$ & Não confirmada \\
\hline $\mathrm{Hb}$ & $\begin{array}{l}\text { As Oportunidades de Crescimento influencia positivamente a informatividade } \\
\text { dos lucros contábeis divulgados pelas empresas negociadas nas bolsas latino- } \\
\text { americanas }\end{array}$ & Confirmada \\
\hline Hc & $\begin{array}{l}\text { O endividamento influencia negativamente a informatividade dos lucros contábeis } \\
\text { divulgados pelas empresas negociadas nas bolsas latino-americanas }\end{array}$ & Não Confirmada \\
\hline
\end{tabular}

Quadro 3: Resumo dos resultados encontrado por hipótese

Considerando os resultados encontrados, seguem as seguintes evidências relacionadas à influência de cada uma das varáveis estudadas sobre a informatividade dos lucros contábeis no conjunto dos mercados estudados da América Latina:

- Tamanho:a partirdos resultados obtidos sobrea amostra de trabalho, houve aindicação de uma influência negativa da variável tamanho (TAM) sobre a informatividade dos lucros contábeis das empresas latino-americanas. Por conseguinte, os resultados encontrados não confirmaram a hipótese (Ha) de que a informatividade dos lucros contábeis das empresas negociadas nos mercados latino-americanos é positivamente relacionada com o tamanho da empresa.

- Oportunidades de Crescimentos: o resultado obtido para a variável oportunidades de crescimentos, mensurado a partir do índice Market-to-book (MTB), verificou uma relação positiva com a informatividade dos lucros contábeis. Este resultado confirma a hipótese $(\mathrm{Hb})$, indicando que a variável oportunidades de crescimentos influencia positivamente a informatividade do lucro contábil das empresas negociadas nos mercados latino-americanos.

- Endividamento: não foi verificada a associação da variável endividamento (END) com a informatividade dos lucros contábeis na amostra de trabalho (América Latina). Estes resultados não confirmam a hipótese $(\mathrm{Hc})$ de que o endividamento influencia negativamente a informatividade dos lucros contábeis na América-Latina.

Ainda em relação à amostra de trabalho, devem-se destacar os resultados obtidos pelas variáveis binárias país e ano. Os resultados indicam que a informatividade dos lucros contábeis varia entre os mercados estudados. Com exceção do ano de 2006, a informatividade dos lucros contábeis também apresentou diferenças significativas entre todos os anos.

Como o objetivo de gerar um número maior de evidências, como fontes complementares, foram obtidos, a partir das sub-amostras individuais representativa de cada mercado, os seguintes resultados:

\begin{tabular}{|c|c|c|c|c|c|c|}
\hline Hipóteses & Variável & Argentina & Brasil & Chile & México & Peru \\
\hline $\mathrm{Ha}$ & LLA.TAM & $(?)$ & $(?)$ & $(?)$ & $(?)$ & $(?)$ \\
\hline $\mathrm{Hb}$ & LLA.MTB & $(+)$ & $(+)$ & $(+)$ & $(+)$ & $(+)$ \\
\hline $\mathrm{Hc}$ & LLA.END & $(?)$ & $(?)$ & $(?)$ & $(?)$ & $(?)$ \\
\hline
\end{tabular}

Quadro 4: Resumo dos resultados encontrados por mercado

Conforme os resultados listados no Quadro 4, somente a variável oportunidades de 
crescimento (MTB) apresentou relação estatisticamente significante com a informatividade dos lucros contábeis em todos os mercados pesquisados. As evidências encontradas em todas as sub-amotras sugerem que as oportunidades de crescimento representadas pelo índice marketto-book (MTB) exercem influencia positiva sobre a informatividade dos lucros contábeis. Esta evidência indica que, para todos os mercados acionários da Argentina, Brasil, Chile, México e Peru, a informatividade dos lucros contábeis será maior, quanto maiores forem as oportunidades de crescimento futuras das empresas negociadas.

Os resultados obtidos pelas amostras individuais sobre cada mercado/país não confirmaram a influência negativa da variável tamanho (TAM) sobre a informatividade dos lucros contábeis, tal como registrado na amostra de trabalho. Os resultados sobre a variável endividamento (END) também não indicaram, para todos os mercados pesquisados, que esta variável exerce alguma influência sobre a informatividade dos lucros contábeis.

De forma conclusiva, analisando o conjunto de evidências levantadas sobre todos os resultados gerados, tanto pela amostra de trabalho, quanto pelas sub-amostras, pode-se estabelecer que, entre as variáveis estudadas, somente a variável oportunidades de crescimento, representada pelo índice market-to-book, exerceu influência sobre a informtividade dos lucros contábeis divulgados pelas empresas negociadas nos principais mercados acionários da Argentina, Brasil, Chile, México e Peru durante o período analisado, de 2005 a 2008.

Por fim, como indicação para futuras pesquisas, sugere-se a investigação da influência de outras variáveis sobre a informatividade dos lucros contábeis das empresas negociadas na América-Latina, em especial são indicadas as pesquisas sobre as variáveis relacionadas ao ambiente de governança corporativa, tal como a aplicação de práticas diferenciadas de governança corporativa, ou a estrutura acionária, tal como a concentração de votos e diferença entre os direitos de voto e de fluxo de caixa.

\section{REFERÊNCIAS}

ATIASE, Rowland. Predisclosure information, firm capitalization and security price behavior around earnings announcements. Journal of Accounting Research, p. 21-36. Spring 1985.

BALL, Ray; BROWN, Philip. An empirical evaluation of accounting income numbers. Journal of Accounting Research, v. 6, p. 159-178, 1968.

BERNARDO, H. P. Avaliação empírica do efeito dos anúncios trimestrais do resultado sobre o valor das ações no mercado brasileiro de capitais - um estudo de evento. Dissertação (Mestrado em Ciências Contábeis) - Departamento de Contabilidade e Atuária - FEA/USP. 2001.

BOARD, J. G. L.; WALKER, M. Intertemporal and cross-sectional variation in the association between unexpected accounting rates of returns and abnormal returns. Journal of Accounting Research, v. 28, n. 1, Spring 1990.

BROWN, Philip. The impact of the annual net profit report on the stock market. The Australian Accountant, p. 277-283, Jul. 1970.

BUSHMAN, Robert; CHEN, Qi; ENGEL, Ellen; SMITH, Abbie. Financial accounting information, organizational complexity and corporate governance systems. Journal of 
Accounting and Economics, v. 37, p. 167-201, 2004.

BUSSAB, Wilton de O.; MORETIN, Pedro A. Estatística básica. 5.ed. São Paulo: Saraiva, 2005.

CHANEY, Paul; JETER, D. The effect of size on the magnitude of long-window earnings response coefficients. Contemporary Accounting \& Economics, v. 28, 2, p. 83-115, 1992.

COLLINS, Daniel; KOTHARI, S.P. An analysis of intertemporal and cross-sectional determinants of earnings response coefficient. Journal of Accounting and Economics, v. 11, p. 143-81, 1989.

COLLINS, Daniel; PINCUS, Morton; XIE, Hong. Equity valuation and negative earnings: role of book value of equity. The Accounting Review, v. 74, p. 29-61, 1999.

DHALIWAL, Dan; LEE, K.; FARGHER, Neil. The Association between unexpected earnings and abnormal security returns in the presence of financial leverage. Contemporary Accounting Research, v. 8, p. 20-41, 1991.

EASTON, Peter D.; HARRIS, T. Earnings as an explanatory variable for returns. Journal of Accounting Research, v. 29, 1, p. 19-36, 1991.

FAN, Joseph; WONG, T. J. Corporate ownership structure and the informativeness of accounting earnings in East Asia. Journal of Accounting and Economics, v. 33, p. 401-425, 2002.

FIRTH, M., The relative information content of the release of financial results data by firms. Journal of Accounting Research, v. 19, p. 521-529, Autumn 1981.

FORSGARDH, I.E.; HERTZEN, K. The adjustment of stock prices to new information. In: ELTON, E.J.; GRUBER, M. J. (Eds.). International capital markets. Amsterdam: NorthHolland, 1975. p. 68-86.

FOSTER, George. Accounting earnings and stock prices of insurance companies. The Accounting Review, v. 50, p. 686-698, Oct. 1975.

FRANCIS, Jennifer; SCHIPPER, Katherine. Have financial statements lost their relevance? Journal of Accounting Research, v. 37, p. 319-352, 1999.

FRANCIS, Jennifer; SCHIPPER, Katherine; VINCENT, Linda. Earnings and dividend informativeness when cash flow rights are separated from voting rights. Journal of Accounting and Economics, v. 39, p. 329-360, 2005.

FREEMAN, Robert. The Association between Accounting Earnings and Security Returns for Large and Small Firms. Journal of Accounting and Economics, v. 9, p. 195-228, 1987.

KNIGHT, R.F. The Association between published accounting data and the behavior of share prices. Unpublished doctoral thesis. Cape Town: University of Cape Town, 1983.

KOTHARI, S.P. Capital markets research in accounting. Cambridge: Dez. 2000. Disponível em: <http://web.mit.edu/kothari/www>. Acesso em: 23 maio 2002. 
LEV, Baruch; AMIR, Eli. Value Relevance of nonfinancial information: the wireless communications industry. Journal of Accounting and Economics, v. 22, 1996.

LOPES, A. B. A relevância da informação contábil para o mercado de capitais: o Modelo de Ohlson aplicado à Bovespa. 2001. Tese (Doutorado em Controladoria e Contabilidade) - Departamento de Contabilidade e Atuária, Faculdade de Economia, Administração e Contabilidade, Universidade de São Paulo.

MARTINEZ, Antônio Lopo. Gerenciamento dos resultados contábeis: estudo empírico das empresas abertas brasileiras. São Paulo, 2001. Tese (Doutorado em Ciências Contábeis) Faculdade de Economia, Administração e Contabilidade da Universidade de São Paulo.

SARLO NETO, Relação entre a estrutura de propriedade e a informatividade dos lucros contábeis no mercado brasileiro. São Paulo, 2009. Tese (Doutorado em Contabilidade) Programa de Pós-Graduação em Contabilidade, Universidade de São Paulo.

SCHIEHLL, Eduardo. O efeito da divulgação das demonstrações financeiras: um estudo sobre a variação das ações. Porto Alegre, 1996. Dissertação (Mestrado em Administração) Programa da Pós-Graduação em Administração, Universidade Federal do Rio Grande do Sul.

SOARES, Rodrigo Oliveira; ROSTANO, Luciano Martin; SOARES, Karine Talamini Costa. Estudo de evento: o método e as formas de cálculo do retorno anormal. In: ENCONTRO DA ASSOCIAÇÃO NACIONAL DE PÓS-GRADUAÇÃO EMADMINISTRAÇÃO - ENANPAD, 26. 2002, Salvador. Anais eletrônicos... Rio de Janeiro: ANPAD, 2002. CD-ROM.

STRONG, N.; WALKER, M. The explanatory power of earning for stock returns. The Accouting Review, v. 66, n. 2, Apr. 1993.

WHITE, H. A Heteroscedasticity Consistent Covariance Matrix Estimator and a Direct Test of Heteroscedasticity. Econometrica, v.48, 1980, pp. 817-818. 


\section{ENDEREÇO DOS AUTORES:}

\section{Alfredo Sarlo Neto}

Universidade Federal do Espírito Santo, Centro de Ciências Jurídicas e Econômicas.

Av. Fernando Ferrari, 1358, Boa Vista

Vitoria, ES - Brasil

29075-505

\section{Bruno Rossi Bassi}

Universidade Federal do Espírito Santo, Centro de Ciências Jurídicas e Econômicas. Av. Fernando Ferrari, 1358, Boa Vista

Vitoria, ES - Brasil

29075-505

\section{André Abreu de Almeida}

Universidade Federal do Espírito Santo, Centro de Ciências Jurídicas e Econômicas, Departamento de Gemologia.

Av. Fernando Ferrari, 541, Goiabeiras

Vitoria, ES - Brasil

29000-000 